\section{Conclusions}

1-Fine Para possesses no distinctadvantage over plantation rubber so far as tensile capacity, speed of cure, or hysteresis endurance are concerned.

2-Excess cure produces lower hysteresis on all cycles than more moderate cure.

3-Under cure produces greater hysteresis on the first cycle, but more rapid decay on following cycles than moderate cure.
4- The chief advantages of a pure gum stock lies not in a higher hysteresis on the first cycle but in:

$a$-Greater capacity to absorb energy prior to rupture.

$b$-Superior hysteresis endurance.

$c$ - Greater rate of extension per rate of energy absorption, hence transfer of energy from airplane to shock absorbers and reverse is slower, thereby setting up lesser stresses in the airplane.

\title{
The Solubility of Gases in Rubber and Rubber Stock and Effect of Solubility on Penetrability ${ }^{1,2}$
}

\author{
By Charles S. Venable and Tyler Fuwa
}

Research Laboratory of Applied Chemistry, Massachusetts Institute of Technology, Cambidge, Mass,

The recent rapid development of rubberized balloon fabric has led to an extensive study of the penetration of gases through rubber and the various factors influencing this penetration. Edwards and Pickering ${ }^{3}$ have shown that for any one gas the rate of penetration through a given sample of rubber is directly proportional to the partial pressure difference and increases rapidly with the temperature. The relative penetrability values obtained by them for various gases are in good agreement with similar values determined by Graham ${ }^{4}$ and Dewar. ${ }^{5}$ Comparable results were also obtained by Daynes. ${ }^{6}$ Since there was no apparent relationship between relative penetrability and density of the gas, Graham postulated that the penetration mechanism consisted in the solution of the gas on one side of the rubber, with a subsequent diffusion of the dissolved gas through the rubber and vaporization on the other side. Later investigators are inclined to take the same view.

Though penetrability is thus made a function of the solubility of the gas in the rubber, the mathematical relationship has been indeterminate on account of the lack of accurate solubility data. By weighing sheets of rubber after exposure to the gas, Wroblewski obtained rough solubility data for nitrous oxide, carbon dioxide, hydrogen, and air. Values were also given for temperature coefficients but all his results were subject to very large experimental error. Hüfner ${ }^{8}$ states that between $0^{\circ}$ and $25^{\circ} \mathrm{C}$. a gray vulcanized rubber stopper in an atmosphere of carbon dioxide absorbs about its own volume of the gas. He finds no absorption for hydrogen and nitrogen, and no absorption for oxygen beyond that involved in oxidation of the rubber. From a study of equilibrium pressures for a known volume of gas in contact with the rubber, Reychler ${ }^{9}$ determined the solubility at $18^{\circ} \mathrm{C}$. of carbon dioxide at 1.06 volumes and sulfur dioxide at 26 volumes per volume of rubber.

Recently Daynes, ${ }^{6}$ by measuring the "lag" or time consumed in saturating the rubber membrane in the Shakespear permeameter, has attempted to separate the permeability coefficient into its absorption or solubility coefficient and its diffusion coefficient. He worked with hydrogen, carbon dioxide, nitrous oxide, air, oxygen, and ammonia, but his results are open to the criticism that the "lag" period measured

1 Presented before the Division of Rubber Chemistry at the 61st Meeting of the American Chemical Society, Rochester, N. Y., April 26 to 29, 1921.

2 Published as Contribution No. 38 from the Research Laboratory of Applied Chemistry, Massachusetts Institute of Technology.

Chem. Met. Eng., 23 (1920), 17, 71.

- Phil. Trans., 156 (1866), 399.

- Proc. Roy. Inst., Gt. Britain, 21 (1915), 558, 813.

- Proc. Roy. Soc. London, 97 A (1920), 286.

'Wied. Ann. Phys., 8 (1879).

I Ibid., 94 (1888), 1.

- J. chim. phys., 8 (1910), 39, 617. must have a relatively large correction applied for instrument lag. His interpretation of results is also somewhat vitiated by curious errors in density values assumed (page 305).

Recently this Laboratory, in connection with an investigation undertaken for the Goodyear Tire \& Rubber Co., has been making a study of the solubility of gases in rubber and rubber stock, using a direct experimental procedure capable of giving more accurate results than any hitherto published.

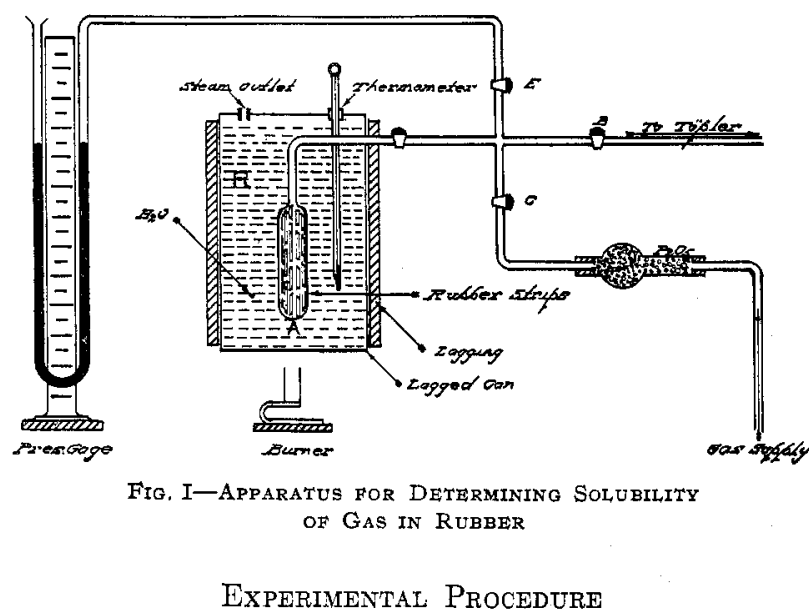

The procedure consisted essentially in leaving thin strips of rubber, from which all dissolved gas had been removed by evacuation, in contact with an atmosphere of the gas under the conditions desired until equilibrium was established. This gas was then pumped out with a Töpler pump and measured over mercury, due correction being made for the void gas in the container system used. This procedure, therefore, in contrast to those previously attempted, allows a direct determination of the volume of gas held in free condition by the rubber.

The apparatus is shown in Fig. I. A weighed amount of rubber cut into thin strips was placed in the glass bulb $\mathrm{A}$. Connections were made through $\mathrm{C}$ with a tube by which the gas (dried over $\mathrm{P}_{2} \mathrm{O}_{5}$ or soda lime) could be introduced into the bulb. By means of stopcock $B$ connection was made with a Töpler pump and by means of $E$ with a mercury manometer. A large water reservoir, $R$, around the bulb served as the means of temperature control.

After the apparatus had been carefully tested for leaks, the rubber was placed under high vacuum for $48 \mathrm{hrs}$. to exhaust all dissolved gases. Preliminary experiments demonstrated that for the thickness of rubber used, and at room temperature, $24 \mathrm{hrs}$. were required for equilibrium to be 
established in the case of all gases save ammonia and sulfur dioxide; at $100^{\circ} \mathrm{C}$., only $2 \mathrm{hrs}$. were required. A corresponding time was used for pumping out the dissolved gas. The time required for equilibrium for ammonia and sulfur dioxide was about twice that for the other gases.

To determine a solubility value, the evacuated rubber was left in contact with the dry gas under the desired conditions until equilibrium was established, as indicated by the constancy of the pressure in the bulb. Stopcocks $\mathrm{C}$ and $\mathrm{E}$ were then closed and the gas (void gas and dissolved gas) in the bulb system ABCE was pumped out and measured. The difference between the total volume and void volume represented the dissolved gas. This quantity was calculated over to the basis of cc. gas (N.P.T.) per $100 \mathrm{cc}$. of raw rubber, or in the case of the compounded samples, cc. gas (N. P. T.) per $100 \mathrm{cc}$. of rubber actually present in the mix.

DETERMINATION OF VOID VOLUME-From gage readings, it was found that when a gas appreciably soluble in rubber was introduced into the bulb, the initial rate of solution was very rapid. Consequently, the void volume was determined by introducing hydrogen into the bulb system containing the evacuated rubber and at the end of 5 min. pumping it out and measuring the gas. Gage readings during that interval had shown that the volume of hydrogen taken up by the rubber was so nearly zero as to be well within the other experimental errors involved. Confirmation of this very low solubility for hydrogen is shown by the fact that when air was introduced into the bulb system and removed after 5 secs.' exposure, the volume of air obtained (260.3 and $260.6 \mathrm{cc}$.) was only very slightly greater than the volume of hydrogen removed (260.02 cc.) after 3 hrs.' exposure to the latter gas.

PRECISION-Duplicate determinations showed the whole procedure to have approximately the precision indicated in Table 1.

TABLE 1

(Solubility cc. gas (N. P. T.) per $100 \mathrm{cc}$, rubber)

$\begin{array}{cc}\text { Values } & \begin{array}{c}\text { Maximum Possible } \\ \text { Deviation } \\ \text { Per cent }\end{array} \\ 3 \text { to } 5 & \text { About } 40 \\ 5 \text { to } 10 & \text { About } 20 \\ 10 \text { to } 25 & \text { About } 10 \\ \text { Above } 25 & \text { About } 5\end{array}$

SAMPLES USED

I. Pale Crepe-From a lot some 3 or 4 yrs. old.

II. Smoked Sheet-Obtained from Akron together with III and IV, It is understood that this same rubber was used in compounding III and IV. III. Original Composition (by wt.)

$\begin{array}{lcl}\text { Smoked sheet } & 100 & \\ \text { ZnO } & 10 & \\ \text { Thiocarbanilide } & 3 & \\ \text { Combined sulfur } & 3.2 \% \text { of wt. smoked sheet } \\ & \text { present } & \\ \text { Original Composition (by wt.) } & & \\ \text { Smoked sheet. } & 100 & \\ \mathrm{ZnO} & 10 & \\ \mathrm{~s} & 20 & \\ \text { Thiocarbanilide } & 0 & \\ \text { Combined sulfur } & 2.56 \% \text { of wt. smoked sheet } \\ & \text { present }\end{array}$

Sample IV obviously contains an abnormal amount of free sulfur.

\section{Experimentai, Results}

EFFECT OF SURFACE-Solubility Determinations made on a sample of rubber cut so that in Case $A$ the surface exposed was about three times that in Case $B$, showed that there was no difference in the amount of gas held by the Rubber $A$ and Rubber B. The effect of surface area is apparently negligible so far as final solubility is concerned, indicating that the gas is held in true solution and not by adsorption on the macroscopic surface of the rubber.

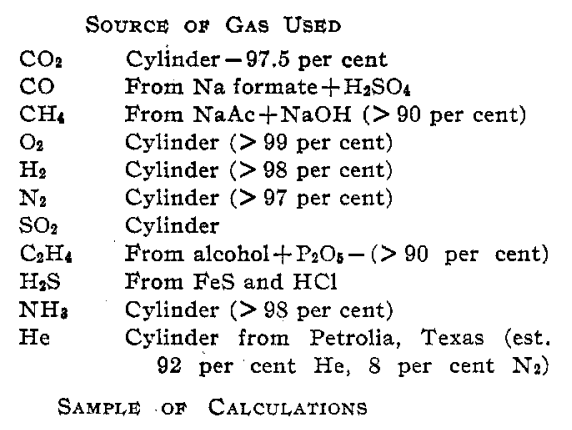

Sample IV. Vulc. coefficient $=2.56$ per cent.

Equilibrium for $24 \mathrm{hrs}$, at room temperature

Wt. sample $=71.1 \mathrm{~g} .=54.7 \mathrm{~g}$. rubber $=59.4 \mathrm{cc}$. rubber

Bulb closed at $23.7^{\circ} \mathrm{C}$. and $771.2 \mathrm{~mm}$. Hg

Gas collected (at $23.7^{\circ}$ and $771.2 \mathrm{~mm}$ ) $=125.9 \mathrm{cc}$.

Void volume (det. with hydrogen) $=67.2 \mathrm{cc}$.

Dissolved gas $=58.7 \mathrm{cc} .\left(23.7^{\circ} \mathrm{C}\right.$. and $\left.771.2 \mathrm{~mm} . \mathrm{Hg}\right)=54.8 \mathrm{cc}$.

(N. P. T. $)=92.2$ cc. per $100 \mathrm{cc}$. rubber

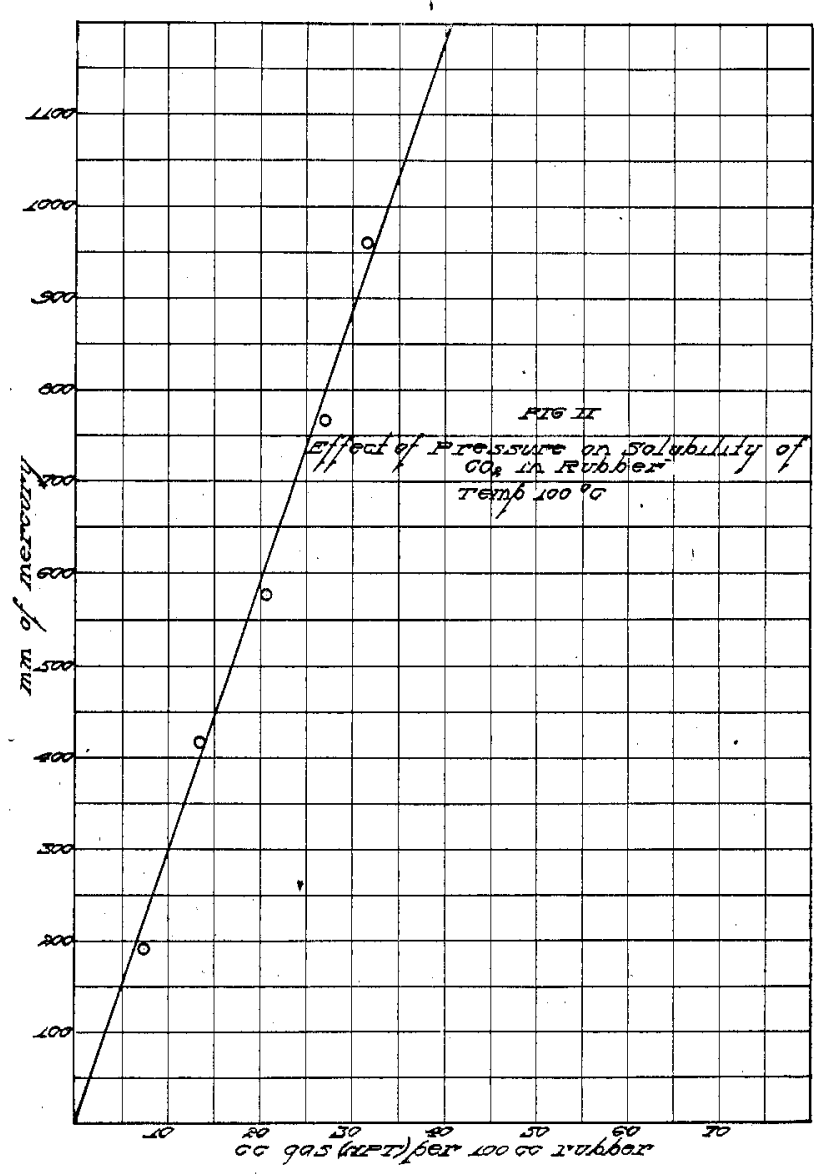

EFFECT OF GRADE OF RUBBER AND VULCANIZATION COEFFICIENT-The effect of the grade of rubber and vulcanization coefficient on the solubility of carbon dioxide at room temperature is shown in Table 2. Since these determinations were made at temperatures ranging from $16^{\circ}$ to $24^{\circ}$. $\mathrm{C}$, the values were calculated to the common basis of $20^{\circ} \mathrm{C}$. by referring to the slope of the curve shown later in Fig. III.

TABLE 2-EFFECT OF GRADE OF RUBBER AND VULCANIZATION COEFFTCIENT ON SOLUBILITY OF $\mathrm{CO}_{2}$ IN RUBBER

Pressure $\mathrm{CO}_{2}=760 \mathrm{~mm}, \mathrm{Hg}$.

Solubility reported in cc. gas (N. P. T.) per $100 \mathrm{cc}$. initial raw rubber SOLUBIIITY

SAMPLE

I. Pale crepe (raw)

II. Smoked sheet (raw)

III. Smoked sheet (vulc. coeff, $=2.56$ )

IV Smoked sheet (vulc. coeff. $=3.2$ )
Observed $\begin{aligned} & \text { Calculated } \\ & \text { to } 20^{\circ} \mathrm{C} \text {. }\end{aligned}$

90 at $21^{\circ} \mathrm{C}$. 92

108 at $16^{\circ} \mathrm{C} . \quad 102$

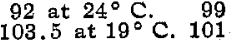


There is a 10 per cent difference between unvulcanized pale crepe and smoked sheet. On the other hand, when smoked sheet is vulcanized to different coefficients up to

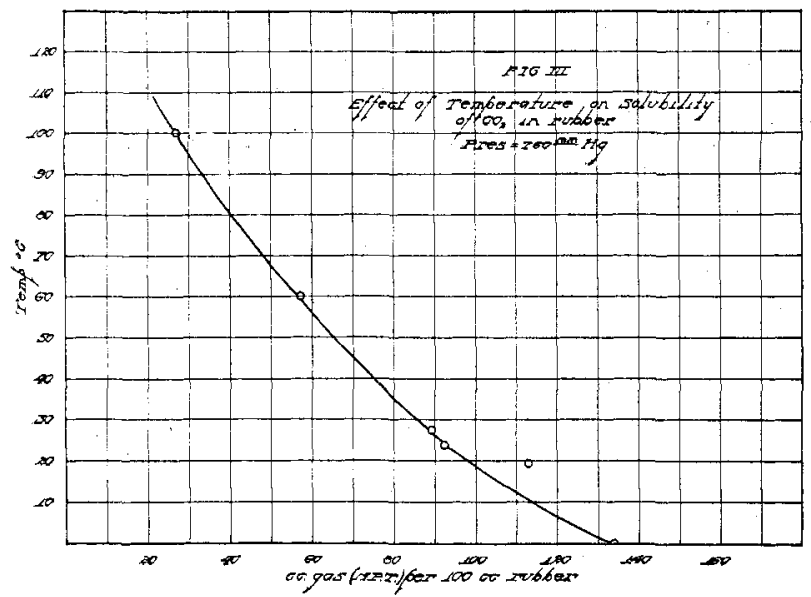

3.2 per cent, there is comparatively little difference between the volume of gas held by $100 \mathrm{cc}$. of the raw rubber and $100 \mathrm{cc}$. of the same rubber after vulcanization. The 10 parts of zinc oxide and 17 parts of free sulfur present also appear to exert no appreciable effect on the solubility when the results are calculated on the basis of the rubber present. Accordingly, free use has been made of either Samples III and IV in obtaining solubility data, though the sample used is always indicated.

EFFEC' OF PRESSURE-A study was made of the effect of pressure on the solubility of carbon dioxide in rubber. These determinations were made at $100^{\circ} \mathrm{C}$., on a sample of rubber from Isot IV. The results are shown in Fig. II.

It will be noted that the solubility is directly proportional to the absolute pressure within the limits investigated. This is additional proof that the gas is held in true solution rather than by adsorption; this evidence rules out the possibility of adsorption even on the surface of the colloidal units of rubber.

EFFECT OF TEMPERATURE-The effect of temperature on the solubility of carbon dioxide in rubber is shown in Fig. III. The rubber was taken from Lot IV, and the pressure was $760 \mathrm{~mm}$. Hg.

The curve is the usual type of solubility curve. Using the solubility equation

$$
\frac{d \log \mathrm{S}}{d t}=\frac{\Delta \mathrm{H}}{\mathrm{RT}^{2}}
$$

and plotting $\log \mathrm{S}$ against $\frac{1}{\mathrm{~T}}$, the points fall fairly well on a straight line. From the slope of this line, $\Delta \mathrm{H}$ (the molal heat of solution of carbon dioxide in rubber) is calculated to be about 3300 cal. It will be noted that the solubility at $140^{\circ} \mathrm{C}$.; or vulcanization temperature, will be very small. In the case of carbon dioxide, the solubility at $100^{\circ} \mathrm{C}$. is about one-third that at $20^{\circ} \mathrm{C}$. As seen from Table 3 , in the case of the other gases the solubility at $100^{\circ} \mathrm{C}$. is usually about one-half that at $20^{\circ}$, indicating a lower heat of solution than for carbon dioxide.

RELATIVE SOLUBILITY OF VARIOUS GASES-The relative solubility of the various gases in rubber is shown in Table 3. Rubber from Lots III and IV was used. The determinations were made at a gas pressure at $760 \mathrm{~mm}$. $\mathrm{Hg}$ and at the temperatures indicated. The critical temperature for each gas is given in degrees Kelvin in Column 5.

As previously explained, the solubility of hydrogen is too low to be determined by the procedure used, and in the above
TABLE 3-SOLUBIUITY OF VARIOUS GASES IN VULCANIZED RUBBER Solubility cc.gas (N.P. T.)

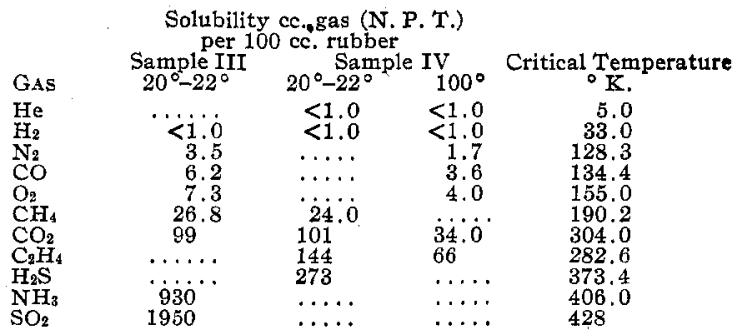

table, it has been indicated simply as less than 1 . The same was found to be the case for helium. Comparing solubilities with critical temperatures, the order of the solubility in rubber of the various gases is the same as the order of their absolute critical temperatures, save in the case of the unsaturated ethylene, which indicates that the degree of solubility is roughly proportional to the ease of condensation of the gas.

In Table 4 are given comparative values of the solubility of the various gases in rubber and in water at $21^{\circ} \mathrm{C}$. The values for water were taken from the Landolt-Börnstein "Tabellen," being largely the figures given by Winkler. In the last column are given the ratios of the solubility in rubber to that in water.

TABle 4-SOLUBILITY OF GASES IN RUBBER AND IN WATER Solubility given in cc. gas (N. P. T.) per $100 \mathrm{cc}$. solvent. Temp. $=21^{\circ} \mathrm{C}$.
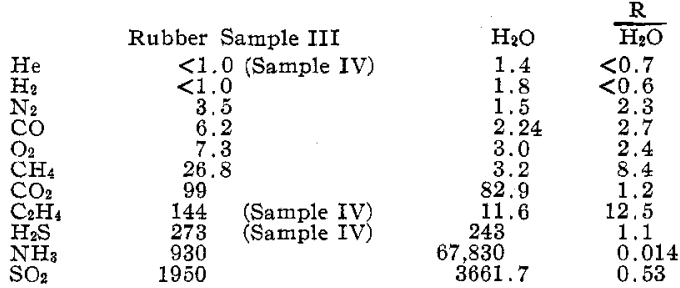

In the case of hydrogen and helium, the exact ratio is unknown, but is evidently small. As would be expected, the two hydrocarbons, methane and ethylene, are much more soluble in rubber than in water, whereas ammonia and sulfur dioxide, which form hydrates in aqueous solution, are much more soluble in water than in rubber. In the case of the other gases, the ratio is fairly constant.

\section{Relationship between Relative Solubility and Rela-} TIVE Penetrability

If the process by which a gas penetrates through a rubber membrane is one of the solution of the gas on one side of the membrane, diffusion of dissolved gas through membrane, and evaporation on the other side, inasmuch as Edwards and Pickering ${ }^{3}$ have shown that for any one gas the rate of penetration is indirectly proportional to the thickness of the membrane, it can be assumed that this rate of penetration is determined by the second stage of the process, that is, diffusion of dissolved gas. The expression for the rate of penetration of a gas through rubber might thus be expected to take the form:

$$
\mathrm{P}=k \mathrm{D} \mathrm{C}
$$

where $k=$ proportionality constant depending upon the condition of the rubber, the temperature, etc.

$\mathrm{D}=$ rate of diffusion of an individual molecule,

$\mathrm{C}=$ concentration of gas in true solution (not including molecules which are combined chemically so as not to be able to move freely).

As a first approximation, it may be assumed that $\mathrm{C}$ is correctly measured by $\mathrm{S}$, the solubility as determined in the previously mentioned experiments, and that $D$, the rate of diffusion through the rubber, is proportional to the dis- 
ordered heat motion of the gas molecule, i.e., inversely proportional to the square root of "the molecular weight. Thus the equation for rate of penetration becomes:

$$
\mathrm{P}=\mathrm{K} \frac{\mathrm{S}}{\sqrt{\mathrm{Mol} \cdot \mathrm{Wt}}} \text { or } \mathrm{K}=\frac{\mathrm{P} \times \sqrt{\mathrm{Mol} . \mathrm{Wt}}}{\mathrm{S}}
$$

where $\mathrm{P}=$ relative penetrability, $\mathrm{S}=$ relative solubility, and $\mathrm{K}=$ proportionality factor depending upon the temperature, etc.

In the following discussion, values reported by Edwards ${ }^{3}$ have been used, as representing the most recent and probably the most accurate work. Carbon monoxide and methane were not investigated by Edwards and, accordingly, the values given by Dewar ${ }^{5}$ and Graham ${ }^{4}$ have been taken. This introduces a slight error, inasmuch as the values given by Edwards and Pickering were obtained at $25^{\circ} \mathrm{C}$. and those given by Dewar and Graham at $15^{\circ} \mathrm{C}$. The figures, however, are for relative penetrability compared to nitrogen and in each case were calculated on the basis of the value given for nitrogen by that particular investigator. Although all gases have not the same temperature coefficient, it is believed that no large error is introduced by assuming the same relative temperature coefficient between $15^{\circ}$ and $25^{\circ}$.

In Table 5, eight gases are considered, for which both relative penetrability and relative solubility values $(N=1)$ are now known. In Column 3 are given values for the term

$$
\mathrm{K}=\frac{\mathrm{P} \times \sqrt{\mathrm{Mol} . \mathrm{Wt}} .}{\mathrm{S}} .
$$

Table 5 shows that for four gases, oxygen, nitrogen, carbon monoxide, and carbon dioxide, whose solubilities vary 28 -fold, there is a fair degree of constancy in the values calculated for $K$ considering the fact that the experimental errors involved in the two determinations might be 10 to 30 per cent. The wide variation in the case of the other four gases-hydrogen, helium, methane, and ammoniaindicates, however, that some fundamental error must have been made in the underlying assumptions involved in the equation.

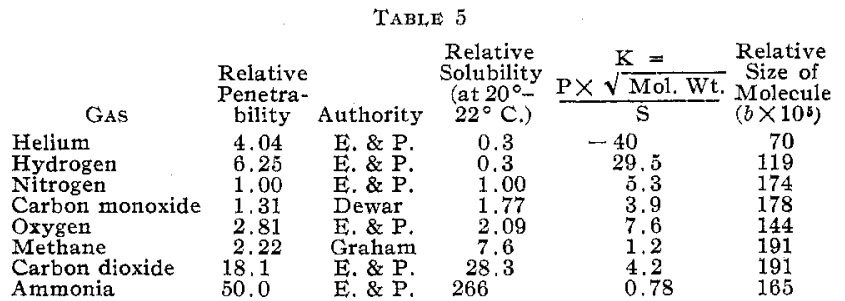

Now, in deriving the expression for $K$, it was assumed that the rate of motion through the rubber is proportional only to the disordered heat motion, that is, inversely as the square root of molecular weight. This totally neglects any other factor, such as the relative size or the structure of the gas molecules, which it is quite reasonable to suppose should influence the rate of diffusion through a colloidal solid such as rubber.

In Column 4 are given relative values of molecular volumes as computed from the quantity $b$ in van der Waal's equation. Pease ${ }^{10}$ has recently shown that these values are in close accord with the Lewis-Langmuir theory. The abnormally high diffusion rate of helium and hydrogen might well be explained on the basis of the relatively small size of gas molecule. Apparently, however, no such relationship holds in the case of the other gases.

If, however, we consider the structure of the molecules from the standpoint of the Langmuir theory, the eight gases readily group themselves into three different classes:

\footnotetext{
so J. Am. Chem. Soc., 43 (1921), 991.
}

1--Helium and nitrogen, which do not form octets, are considerably smaller than the other gases and would be expected to diffuse more rapidly through a given medium.

2-Oxygen, nitrogen, carbon monoxide, and carbon dinxide form either single octets or octets joined together by their faces with no hydrogen nuclei on the outside. This group should behave quite similarly.

3-Methane and ammonia form two very similar molecules with four and three exposed hydrogen nuclei, respectively, on the outside of the octet. It is quite possible that such molecules would diffuse more slowly through the rubber colloid, especially because the rubber hydrocarbon has a large number of unsaturated linkages.

As regards the effect of temperature, in conducting a diffusion at $100^{\circ} \mathrm{C}$. in place of $25^{\circ} \mathrm{C}$., the solubility of the gas is decreased by at least one-half. The disordered heat motion (proportional to the square root of absolute temperature) is increased by less than 15 per cent. On the other hand, Edwards and Pickering ${ }^{3}$ have shown that at $100^{\circ} \mathrm{C}$. the rate of diffusion in the case of carbon dioxide is about six times, and in the case of hydrogen and helium, about seven to eight times that at $25^{\circ} \mathrm{C}$.

It is obvious, therefore, that the value for $K$ in the above formula must increase ten- or twelve-fold for a $75^{\circ}$ rise in temperature. This is, however, not surprising, for while it is somewhat greater than the change in the rate of diffusion. of solutes through water, the order of magnitude is the same, and the coefficient of expansion of rubber is much greater than that for water, and its decrease in "viscosity" would undoubtedly prove correspondingly greater if it could be measured by ordinary methods. The viscosity of heavy oils varies thirty-fold in magnitude over a similar range in temperature.

On the whole, therefore, all the evidence seems to favor the customary assumption that the mechanism by which gas penetrates a rubber membrane is through diffusion of the gas, which is held in true solution. While both the solubility and molecular weight of the gas play their expected part in influencing the speed of diffusion, the size and structure of the gaseous molecule and the viscosity of the rubber itself are additional important factors in determining the precise rate of diffusion. The attempt has been made above to analyze these factors as far as it is possible with the limited amount of data now available, which are admittedly inadequate for positive conclusions.

\section{Summary}

1-It has been found that when rubber absorbs a gas, this gas is, in most cases at least, held in true solution and not by adsorption.

2-In the case of carbon dioxide, which has about an average solubility, the amount of gas thus held in true solution by the rubber is, within the limits investigated, directly proportional to the pressure and is unaffected by degree of vulcanization or the presence of compounding ingredients.

3-The solubility decreases rapidly with increasing temperature.

4-Relative solubility values obtained for various gases show that there is a general relationship, such as might be expected on purely theoretical grounds, between the solubility and the density of a gas, and its relative rate of penetration through rubber. The indications are, however, that the actual size and structure of the gas molecule and the viscosity of the rubber likewise markedly influence this rate of penetration, and in a direction which can be predicted.

\section{ACKNOWLEDGMENT}

The Laboratory wishes to express its appreciation for the helpful coöperation of the Goodyear Tire and Rubber Company and for their courtesy in permitting the publication of these results. 